\title{
Parallel changes in non-photochemical quenching properties, photosynthesis and D1 levels at sudden, prolonged irradiance exposures in Ulva fasciata Delile
}

\author{
Herman Carr *, Mats Björk \\ Botany Department, Stockholm University, Lilla Frescativägen 5, SE-106 91, Stockholm, Sweden
}

Received 4 October 2006; accepted 13 December 2006

Available online 23 December 2006

\begin{abstract}
The photosynthetic response to a sudden and prolonged high irradiance exposure and following recovery at low irradiance were studied with the aim of investigating the ability to withstand and adapt to high irradiance without prior high light adaptation. When thalli of Ulva fasciata, accustomed to a low irradiance $\left(80 \mu \mathrm{mol}\right.$ photons $\left.\mathrm{m}^{-2} \mathrm{~s}^{-1}\right)$, were exposed to a high irradiance $(1500 \mu \mathrm{mol}$ photons $\mathrm{m}^{-2} \mathrm{~s}^{-1}$ ), the D1 protein was rapidly degraded, reaching a steady-state level after $110 \mathrm{~min}$. This was followed by a fast recovery when thalli were transferred to dim light. The overall ability of non-photochemical quenching of chlorophyll fluorescence decreased and levelled off at a sudden and prolonged exposure to high irradiance and followed the same trend as the D1 level with a fast recovery in dim light. Ulva had intrinsic means to acclimate rapidly to high irradiance, when non-photochemical quenching did not operate properly, by maintaining a smaller fraction of high light tolerant PSII assemblages and by maintaining a high non-photochemical quenching capacity of chlorophyll fluorescence in relation to the variable fluorescence. The overall absorption of light (400-700 nm) remained high during the period of high irradiance exposure. When Ulva were deprived of nutrients in the form of PES media the ability of non-photochemical quenching decreased at photoinhibitory conditions. The possible causes for the responses at prolonged irradiance and the mechanisms for the decrease of non-photochemical quenching are discussed, with implications for field measurements.
\end{abstract}

(c) 2006 Elsevier B.V. All rights reserved.

Keywords: Chlorophyll fluorescence; D1-protein; Non-photochemical quenching; Oxygen evolution; Ulva

\section{Introduction}

High irradiances may impose harmful stresses on plants and algae. In marine habitats, there are often drastic and rapid changes of irradiance due to tidal waves [1], and turbidity [2]. These circumstances are apart from irradiances changes encountered both in marine and terrestrial environments, such as an overcast or clear sky and movements of leaf canopies. Especially macrophytes living close to the surface or in the intertidal zone will have to cope with

\footnotetext{
${ }^{*}$ Corresponding author. Mobile: +467364936 89; tel./fax: +468798 8537.

E-mail addresses: carr@botan.su.se (H. Carr), bjork@botan.su.se (M. Björk).
}

periods of exposure to both very low and very high irradiances. Ulva can form free floating and stable mats in sheltered areas where the thallus at the bottom will receive very little light and the top part will bleach $[3,4]$. The top layer can also be subjected to nutrient depletions, i.e. of nitrogen, which, in combination with high irradiancy, can cause partly irreversible photodamage as measured with pulse amplitude modulated (PAM) chlorophyll fluorescence [4]. Ulva can appear and disappear from the same site from week to week c.f. [5]. In calm and enclosed waters, high photosynthetic rates can also increase $\mathrm{pH}$ at the surface of Ulva [6,7]. This will make very little dissolved inorganic carbon (DIC) present as $\mathrm{CO}_{2}$, instead a major part of DIC will be present as $\mathrm{HCO}_{3}^{-}$due to $\mathrm{pH}$ dependent equilibrium reaction of DIC in seawater [8]. 
Macroalgae are known, like terrestrial plants, to be able to deal with excess light that reaches the photosynthetic apparatus in a variety of manners and have developed processes to dissipate captured excess energy. By dissipating excess light energy as heat before it enters the photosystems, the likelihood of producing harmful substances, such as oxygen radicals, is reduced. Harmless dissipation of excess energy as heat in the light gathering antenna is induced by the acidification of the lumen caused by the proton-translocation driven by photosynthetic electron transport $[9,10]$ and the so called zeaxanthin-cycle is commonly associated with heat dissipation. At a low luminal $\mathrm{pH}$, de-epoxidase is activated and converts violaxanthin to zeaxanthin [11]. Zeaxanthin is either believed to act as a quencher itself in the antenna [12] or as a structurally important component in aggregation of light harvesting complex (LHC), which is likely an important part of non-photochemical quenching $[9,13]$. Slower, long term, adaptations to high irradiances have also been reported, such as the reduction of the amount of chlorophyll $[14,15]$. In Ulva, non-photochemical quenching of excess energy is larger in thalli grown in high light compared to low light grown thalli [16] and zeaxanthin levels are higher in Ulva grown in high light [17]. Low light acclimated Ulva, or Ulva suddenly exposed to a large irradiance increase, may therefore be unable to protect itself against a sudden exposure to high irradiance relying only on pigment adjustments or non-photochemical quenching capacities as measured with chlorophyll fluorescence.

Capture of excess energy is likely to result in photoinhibition or photodamage. In Ulva more severe photodamage can be expected at nutrient limiting conditions, while at nutrient sufficient conditions acclimation occurs within a day when Ulva is transferred from low light to high light [18]. PSII has often been in focus for photoinhibitory studies, since it is where linear electron transport is initiated and maintained $[19,20]$. Photo induced damage to the photosynthetic apparatus is likely to occur first at PSII due to the longer life time of excited states of chlorophyll compared to PSI, where damage has mainly been reported at chilling conditions and is in part dependent on electrons from PSII $[21,22]$. P $680^{+}$and the oxygen evolving complex (OEC) are situated on or at the trans thylakoid membrane protein D1 [20], and upon breakdown of the D1 protein the OEC disassociates from the protein [23,24]. The D1-protein of the PSII core is essential for linear electron transport [20]. Even though the protein has a fast turnover rate, at high irradiances D1 degradation can be larger than D1 synthesis [25].

A central importance of the proton motive force generated by photosynthetic electron transport is both to balance the production of ATP for carbon fixation and to maintain an acid environment for the initiation of antenna regulation [26]. Previous investigations have shown that plants that are mutants in the D1 protein function, with a lower ability to maintain the proton motive force due to an impaired electron transport, have a lower ability of non-photochemical quenching $[27,28]$. These circumstances raised the question if the non-photochemical quenching properties in Ulva spp can be negatively affected at photoinhibitory conditions.

By using inhibitors of D1-protein synthesis and by measuring photosynthesis with fluorescence parameters and oxygen evolution many studies have indicated and predicted the importance of D1-dynamics in Ulva spp $[16,17,29]$. However, experiments with actual measurements of D1 proteins levels are few or lacking in Ulva spp. This study was conducted with the aim to investigate the ability to adapt to a sudden exposure to high irradiance in Ulva and to study the ability of non-photochemical quenching of chlorophyll fluorescence at photoinhibitory conditions.

\section{Materials and methods}

\subsection{Material and cultivation}

Ulva fasciata was collected in Zanzibar, Tanzania, from the intertidal and subsequently cultivated vegetatively from a single thallus in the laboratory at the Botany Department, Stockholm University, Sweden. Prior to the experiments $U$. fasciata was acclimated to $80 \mu \mathrm{mol}$ photons $\mathrm{m}^{-2} \mathrm{~s}^{-1}$ for at least two weeks in Plexiglas cylinders containing $10-121$ of natural seawater $\left(33 \mathrm{psu}, 25^{\circ} \mathrm{C}\right)$ and illuminated from one side with fluorescence tubes. Seawater was changed approximately two times per week and PES, excluding vitamins [30] (without nitrogen, nitrogen was added separately at the same time as $820 \mu \mathrm{M} \mathrm{NaNO}_{3}$ ) was added as to achieve an $F_{\mathrm{v}} / F_{\mathrm{m}}$ value of at least 0.7 and above. Nutrient deficient $U$. fasciata was deprived of nutrients in the form of PES media and nitrogen for approximately one and a half weeks. Thalli were kept in motion inside the cylinders by introducing a gentle stream of air bubbles from an inlet at the bottom of the cylinders. The pieces were not allowed to grow larger than approximately one $\mathrm{dm}^{2}$, which was achieved by regularly tearing the thalli apart. Ulva lactuca L. was brought from a laboratory cultivation originating from one thallus at the Kristineberg Marine Research Station in Fiskebäckskil on the Swedish west coast, and was acclimated in Stockholm University at similar conditions as nutrient sufficient $U$. fasciata.

\subsection{Experimental set-up at high light exposure}

Algae were exposed to approximately $1500 \mu \mathrm{mol}$ photons $\mathrm{m}^{-2} \mathrm{~s}^{-1}$ PAR, measured inside the glass bottle with a photometer (IL1400A, International Light) for up to $240 \mathrm{~min}$ (390 $\mathrm{min}$ in some cases). Light was supplied from the side by two $400 \mathrm{~W}$ lamps, (Powerstar HQI-BT, Osram). The algal density at the start of an experiment was $2.5 \mathrm{~g}$ alga per 1 seawater in two 4-1 spherical glass bottles. At $15,60,110$ and $240 \mathrm{~min}$, as well as for recovery, three $\mathrm{g}$ composed of at least three thalli were removed for protein 
analysis. U. fasciata thalli were exposed to high light for longer time periods than $240 \mathrm{~min}$ and up to $390 \mathrm{~min}$ for D1 analyses and for measurements of $F_{0}$ and $F_{\mathrm{m}}$. The D1 and fluorescence data at $240 \mathrm{~min}$ and up to $390 \mathrm{~min}$ were presented as an average and given the average time of $300 \mathrm{~min}$. For the experiments of oxygen evolution measurements and quenching analysis a lesser amount of Ulva was removed. Prior to measurements of $F_{\mathrm{v}} / F_{\mathrm{m}}$, oxygen evolution or quenching analysis, the samples were dark-adapted for $10 \mathrm{~min}$. All data collection was repeated on separate occasions, apart from the spectrophotometer analyses that occurred at two occasions, where on one occasion, two independent bottles were used and counted as two repetitions.

\subsection{D1-blot}

Approximately $3 \mathrm{~g}$ of $U$. fasciata or $U$. lactuca were cut with a razor blade and then homogenized in a mortar in $20 \mathrm{mM}$ TES buffer, pH 8.0, containing $900 \mathrm{mM}$ mannitol. The mannitol concentration is less than previously used for isolation of Laminaria chloroplasts [31], to ensure that the media had less density than the chloroplast in order to be able to centrifuge the chloroplasts to a pellet. After homogenisation of the tissue, the mixture was filtered through a four-layer elastic cloth. Complete mini EDTAfree protease inhibitor cocktail (Roche Diagnostics Scandinavia $\mathrm{AB}$, Bromma, Sweden) (at the concentration one tablet per $10 \mathrm{ml}$ ) was added to the filtrate. The filtrate was centrifuged in Eppendorf tubes for $6 \mathrm{~min}$ at $600 \mathrm{~g}$ to remove cell debris. The supernatant was collected and centrifuged at $5000 \mathrm{~g}$ [31] for $8 \mathrm{~min}$ and the chloroplasts were collected as a pellet. The supernatant was removed and the pellet was solubilized with $3.5 \mathrm{ml}$ of $4 \%$ SDS buffer [32] (with the difference that Complete mini-EDTA free protease inhibitor and $100 \mathrm{mM}$ DTT were added instead of PMSF and $100 \mathrm{mM}$ and 2-mercaptoethanol respectively). The SDS-buffer was heated at $96^{\circ} \mathrm{C}$ for $10 \mathrm{~min}$ or until most of the chloroplast pellet had dissolved. The chloroplast solution was then centrifuged at $10,000 \mathrm{~g}$ for $10 \mathrm{~min}$ before collecting the supernatant. Thereafter acetone (99\%) chilled to $-20^{\circ} \mathrm{C}$ was added to the supernatant to give a final concentration of $70 \%$ acetone. This was stored at $-20{ }^{\circ} \mathrm{C}$ in a freezer overnight to precipitate the proteins. The acetone-protein solution was centrifuged at $14,000 \mathrm{~g}$ for $20 \mathrm{~min}$. The pellet was then washed in acetone three times and allowed to dry in Eppendorf-tubes kept on ice. The pellet was solubilised by heating at $96^{\circ} \mathrm{C}$ in $4 \%$ SDS buffer containing $100 \mathrm{mM}$ DTT to break disulfide bonds, no protease inhibitor was added since resolubilization of proteins in SDS buffer after precipitation in acetone does not yield active proteases [33].

The relative protein concentration was measured in a spectrophotometer at $280 \mathrm{~nm}$ in order to load equal amounts of total protein on gels. The samples were then loaded on $10 \%$ or $15 \%$ SDS TRIS-gels (Bio-rad Laboratories, Hercules, California). Electrophoresis was performed using the Mini-Protean 3 Cell system (Bio-rad) at $130 \mathrm{~V}$. The gels were stained with Bio-Safe Coomassie (BioRad). If unequal amounts of proteins between the different lanes were detected visually, the gel was run again with a corrected amount of the protein solution added. The gels were blotted onto PVDF membranes in the Mini TransBlot Electrophoretic Transfer Cell system (Bio-Rad) for approximately seven hours at $30 \mathrm{~V}, 90 \mathrm{~mA}$. The membrane was blocked for non-specific binding in TBS-T 5\% milk at $4{ }^{\circ} \mathrm{C}$ overnight, following the procedures of the ECL plus Western Blotting Detection System (Amersham Pharmacia Biotech). The dilution of the primary anti-body, anti-PsbA global raised in hen (AgriSera, Vännäs, Sweden) was 1:7000 and the secondary anti-body, anti-chicken $\operatorname{lgG}$ coupled to HRP (Sigma, Sigma-Aldrich Corporation, International), was diluted to 1:22,000. The anti-body binding was detected using the ECL + plus Western Blotting Detection System (Amersham Pharmacia Biotech) and scanned in Typhoon 8600 Variable Mode Imager (Amersham Pharmacia Biotec). The amounts of D1 were measured by using the software Image Quant (Molecular Dynamics www.mdyn.com) and normalized to the control that was set to $100 \%$ (Fig. 1). The MW was determined by directly photographing the membrane with transferred proteins and markers before washing off the "Bio-Safe Coomassie" stain of proteins in methanol and overlapping the photographed membrane with a corresponding typhoon scanned photo.

\subsection{PSII fluorescence measurements}

Samples that had been exposed to high irradiances for different periods of time of up to $240 \mathrm{~min}$, and also samples that were allowed to recover in dim light $(2-3 \mu \mathrm{mol}$ photons $\mathrm{m}^{-2} \mathrm{~s}^{-1}$ ) for up to $180 \mathrm{~min}$, were dark adapted for $10 \mathrm{~min}$ before chlorophyll fluorescence induction curves were carried out using a PAM 2000 (Walz, Effeltrich, Germany), Pulse Amplitude Modulated fluorometer. By applying a saturating pulse of white light on top of the low intensity PAM measuring light, $Q_{A}$, an electron acceptor in the electron transport chain, becomes reduced and since the excited electrons from PSII cannot travel further maximal fluorescence is emitted. $F_{\mathrm{m}}^{\prime}$ and $F_{\mathrm{m}}$ were the maximal fluorescence in actinic light and dark adapted samples respectively. $F_{\mathrm{t}}$ was steady state fluorescence in actinic light and $F_{0}$ was the minimal fluorescence in a dark adapted sample. $F_{0}^{\prime}$ was determined as the lowest value within a $5 \mathrm{~s}$ period of far-red light illumination to oxidise reduced compounds of the electron transport chain that affects the redox-state of PSII. Non-photochemical quenching was measured as a light induced quenching of the maximal fluorescence. The induction curves were started by applying an actinic irradiance of approximately $1000 \mu \mathrm{mol}$ photons $\mathrm{m}^{-2} \mathrm{~s}^{-1}$, and lasted for a duration of $190 \mathrm{~s}$. This was done in order to determine $q_{\mathrm{P}}=\left(F_{\mathrm{m}}^{\prime}-F_{\mathrm{t}}\right) /\left(F_{\mathrm{m}}^{\prime}-F_{0}^{\prime}\right)$ and $q_{\mathrm{N}}=$ $\left(F_{\mathrm{m}}-F_{\mathrm{m}}^{\prime}\right) /\left(F_{\mathrm{m}}-F_{0}^{\prime}\right)$ and NPQ $=\left(F_{\mathrm{m}}-F_{\mathrm{m}}^{\prime}\right) / F_{\mathrm{m}}^{\prime}$. At the time points when Ulva was collected for protein analysis, 
minimal and maximal fluorescence were measured in dark adapted samples.

\subsection{PSII fluorescence quenching in thalli cultivated with or without PES media}

For analysis of chlorophyll fluorescence quenching at normal and low DIC conditions, U. fasciata had been cultivated at two different nutrient conditions prior to the experiments. High or normal nutrient sufficient alga was cultivated with PES media as described in Section 2.1 and had an average $F_{\mathrm{v}} / F_{\mathrm{m}}$ value of 0.76 at the start of PSII fluorescence quenching measurements. Nutrient deficient $U$. fasciata was deprived of PES media as described in Section 2.1 and had an average $F_{\mathrm{v}} / F_{\mathrm{m}}$ value of 0.41 at the start of the PSII fluorescence quenching measurements. For the measurements of fluorescence quenching in normal and low DIC concentrations the alga was mounted in a custom made flow through seawater chamber. The chamber consisted of a tubular Plexiglas cylinder of approximately $200 \mathrm{~mL}$ with a water inlet at the top and an outlet at the side close to the bottom. The chamber was sealed from the top with a circular Plexiglas lid with an O-ring. Inside the chamber a small algal piece was mounted on a cylindrical plastic net with the help of rubber bands, the net itself was mounted on a circular piece on the inside of the top seal. Light was directed from the side of the chamber and was measured to $1000 \mu \mathrm{mol}$ photons $\mathrm{m}^{-2} \mathrm{~s}^{-1}$ inside the chamber with a photometer (IL1400A, International Light). However, since the alga was in an approximately $50-55^{\circ}$ angle in direction to the light, a reduction of $20 \%$ of incoming light was calculated as described previously [30], which gives approximately $800 \mu \mathrm{mol}$ photons $\mathrm{m}^{-2} \mathrm{~s}^{-1}$. The optical fibre of the PAM fluorometer (Walz DivingPAM fluorometer, Walz, Effeltrich, Germany) was fitted into a custom made insertion, or plug, of Plexiglas into the chamber, which brought the optical fibre within a few $\mathrm{mm}$ from the alga in a $50^{\circ}$ angle. The actinic light source was supplied from a Halogen lamp with fibre optics (Schott KL 1500 electronic, Schott, Wiesbaden, Germany). Seawater was pumped through the chamber at a flow rate of approximately $21 / \mathrm{h}$. After three hours of light exposure, with dark periods of approximately $6-10 \mathrm{~min}$ inserted after each hour, natural seawater was exchanged to artificial seawater containing $50 \mu \mathrm{M}$ total dissolved inorganic carbon (tDIC) $\left(\mathrm{NaHCO}_{3}\right)$. This was followed by two hours of light exposure at low DIC concentration. Similar to the run in high DIC concentration, dark periods of approximately 6-10 min were inserted after each hour of light exposure. Previously $U$. fasciata had been run in artificial seawater of $2000 \mu \mathrm{M}$ tDIC and compared to natural seawater in the same system and no differences in physiological response in Ulva were detected between the two media. The $50 \mu \mathrm{M}$ tDIC at $\mathrm{pH} 8.2$ was used to obtain similar $\mathrm{CO}_{2}$ concentrations to those corresponding to higher $\mathrm{pH}$ where the DIC species are mainly present as $\mathrm{HCO}_{3}^{-}$and $\mathrm{CO}_{3}^{-2}$ and hardly any $\mathrm{CO}_{2}$, due to $\mathrm{pH}$ dependent equilibrium reactions in seawater [8]. Since Ulva can induce a direct uptake of $\mathrm{HCO}_{3}^{-}$under certain circumstances [34], low DIC media, instead of high $\mathrm{pH}$ media, was chosen to be able to clearly monitor the effects of carbon deficiency on photosynthetic processes. Artificial seawater was prepared as described previously by adding salts to distilled water [35], $50 \mu$ molar $\mathrm{NaHCO}_{3}^{-}$was added to the media and $\mathrm{NaOH}$ and $\mathrm{HCl}$ were used to set $\mathrm{pH}$ 8.2. The natural seawater and the low carbon media were kept in two separate airtight water bags of 8 and 41 respectively (Ortlieb, water proof outdoor gear, Germany). The water was pumped from the water bags in to the chamber using a Masterflex peristaltic pump (Cole-Parmer Instrument Co. Chicago, USA) with flow controlled by Masterflex, Solid State Speed control (Cole-Parmer Instrument Co. Barrington, USA).

\subsection{Oxygen evolution}

Oxygen evolution was measured simultaneously with electron transport rates (ETR) of PSII, in an experimental set-up described previously [31]. The measurements were conducted at a saturating but not photoinhibitory irradiance of $250 \mu \mathrm{mol}$ photons $\mathrm{m}^{-2} \mathrm{~s}^{-1}$ in thallus samples that had been exposed for different periods of time (up to $240 \mathrm{~min})$ to high irradiances $\left(1500 \mu \mathrm{mol}\right.$ photons $\left.\mathrm{m}^{-2} \mathrm{~s}^{-1}\right)$ and in samples that had recovered in dim light up to $180 \mathrm{~min}$.

\subsection{Spectrophotometric measurements}

Tissue absorptance was measured at 400-700 $\mathrm{nm}$ with a S2000 Miniature Fibre Optic Spectrometer (Ocean Optics, Winter Park, FL) in samples that had been exposed for different periods of time to high irradiances and in samples that had subsequently recovered in dim light. Measurements were carried out at two occasions of exposure to high irradiance and at one of the occasions two independent glass bottles were used giving a total of three repetitions. At each repetition absorptance was measured at least three times for all sample tissues. The $U$. fasciata tissue was held in place between two glass-slides with a paper diffuser to scatter the light evenly. Transmittance was also measured at the same wavelengths to calculate the overall absorptance of the tissue as mean absorptance $(=1-$ mean transmittance).

\section{Results}

\subsection{D1 levels, PSII chlorophyll fluorescence and oxygen evolution}

During the initial $1-2 \mathrm{~h}$ of exposure to $1500 \mu \mathrm{mol}$ photons $\mathrm{m}^{-2} \mathrm{~s}^{-1}$ there were large decreases in the amount of D1-protein and the maximal quantum yield $\left(F_{\mathrm{v}} / F_{\mathrm{m}}\right)$, which thereafter levelled off (Figs. 1 and 2a). Maximal quantum yield dropped faster, and to relatively lower values, than 

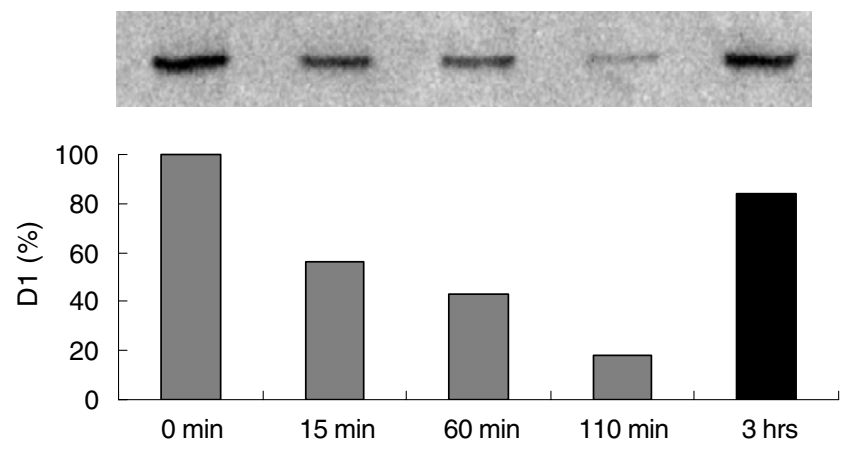

Fig. 1. Amount of D1 protein in $U$. fasciata as a function of exposure time to $1500 \mu \mathrm{mol}$ photons $\mathrm{m}^{-2} \mathrm{~s}^{-1}$ compared to the unexposed control ( $0 \mathrm{~min})$, light grey bars, plus the amount of D1 after a recovery period of $3 \mathrm{~h}$ in dim light following a period of $110 \mathrm{~min}$ of exposure to high irradiance, dark bar.
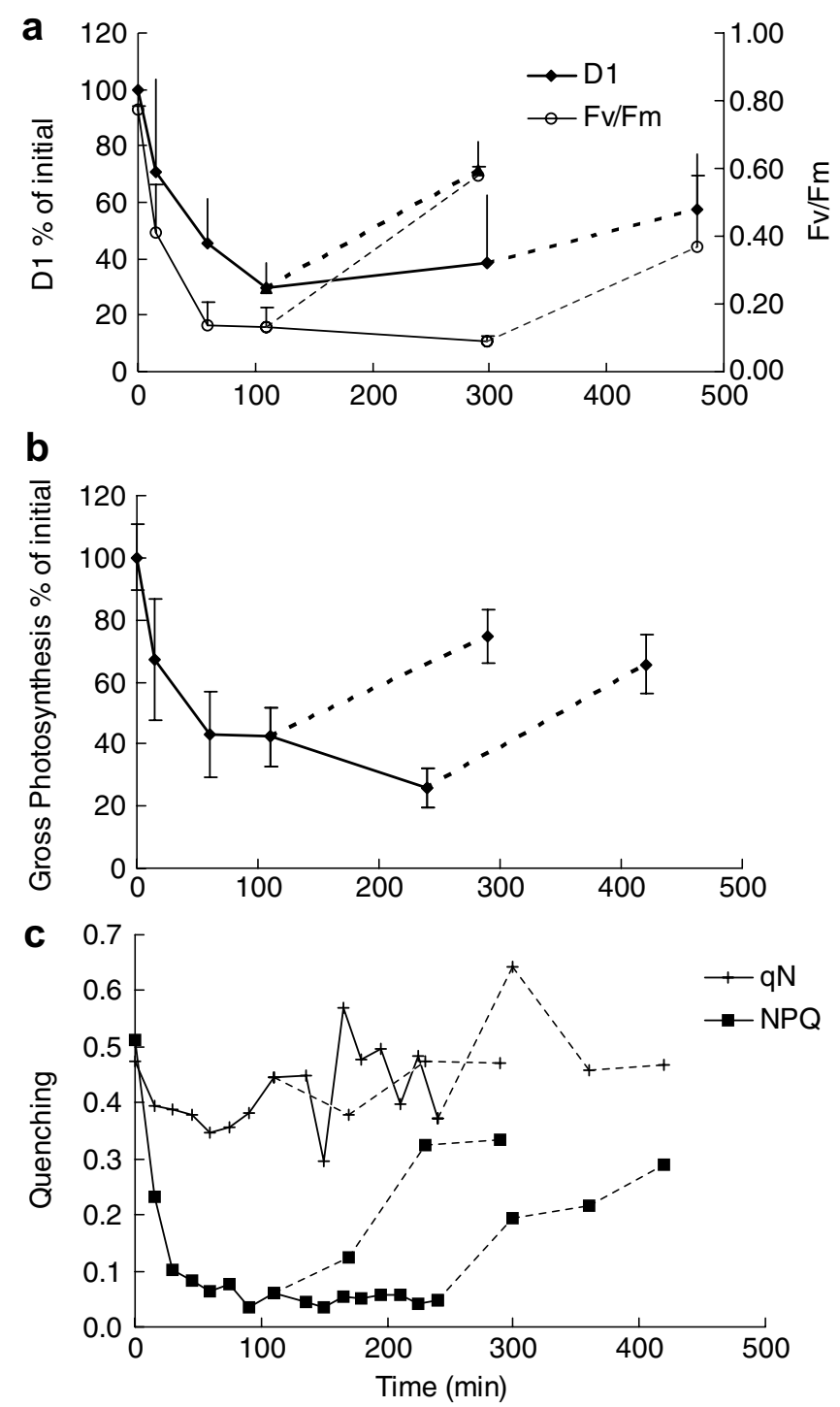

Fig. 2. The effect of $1500 \mu \mathrm{mol}$ photons $\mathrm{m}^{-2} \mathrm{~s}^{-1}$ (solid lines) and corresponding recovery in dim light after high irradiance (dashed lines) on the amount of $\mathrm{D} 1$ protein (diamonds) and $F_{\mathrm{v}} / F_{\mathrm{m}}$ (circles) (a), on gross oxygen evolution (b) and on the ability of NPQ (squares) and $q_{\mathrm{N}}$ (ticks) (c), in $U$. fasciata ( $n=4-6$, bars represent SD). the levels of D1 protein. The same was also shown for $U$. lactuca, however here the degradation of D1 levelled off at approximately $50 \%$ as compared to the control (Fig. 3), whereas in U. fasciata it levels off at approximately $30 \%$ (Fig. 2a). There was also a rapid decrease in the gross photosynthetic oxygen evolution during the first hour of high light exposure, thereafter the decline in oxygen evolution was slower for both $U$. fasciata (Fig. 2b) and $U$. lactuca (not shown). In both $U$. fasciata (Fig. 2c) and $U$. lactuca (not shown and identical to $U$. fasciata) $q_{\mathrm{N}}$ remained high, even after longer exposure periods of high irradiances, while NPQ rapidly drops during the first hour and stays low. After 110 and $240 \mathrm{~min}$ of high light exposure NPQ recovered to approximately $65 \%$ and $55 \%$ respectively of initial values after three hours in dim light (Fig. 2c).

There was also a sharp and rapid decrease in $F_{\mathrm{m}}$ during the first half hour of high light exposure concurrent with an increase of $F_{0}$ (Fig. 4). Thereafter $F_{\mathrm{m}}$ remained low and close to the level of $F_{0}$ that was approximately $50 \%$ higher after $60 \mathrm{~min}$ of high light exposure compared to its original value. After 110 and $240 \mathrm{~min}$ of high light exposure and subsequent recovery for three hours in dim light, $F_{\mathrm{m}}$ recovered to $60 \%$ and $50 \%$ respectively of the initial values. $F_{0}$ remained higher than its initial value after high light exposures in both 110 and $240 \mathrm{~min}$ and after three hours in dim light (Fig. 4).

\subsection{PSII chlorophyll fluorescence quenching at high and low nutrient}

At the onset of light at $800 \mu \mathrm{mol}$ photons $\mathrm{m}^{-2} \mathrm{~s}^{-2}$ there was a drop in $F_{\mathrm{m}}^{\prime}$ corresponding to an increase in NPQ both in the nutrient sufficient and deficient $U$. fasciata (Fig. 5). This drop was accompanied by an increase in $\left(F_{\mathrm{m}}^{\prime}-F_{\mathrm{t}}\right) / F_{\mathrm{m}}^{\prime}$ at the first hour. In both samples there was an acclimation to the high irradiance with lower NPQ values and higher $\left(F_{\mathrm{m}}^{\prime}-F_{\mathrm{t}}\right) / F_{\mathrm{m}}^{\prime}$ values after one hour compared to the data at the onset of light. When the media was changed to a low dissolved inorganic carbon concentration, only the nutrient sufficient Ulva displayed a higher

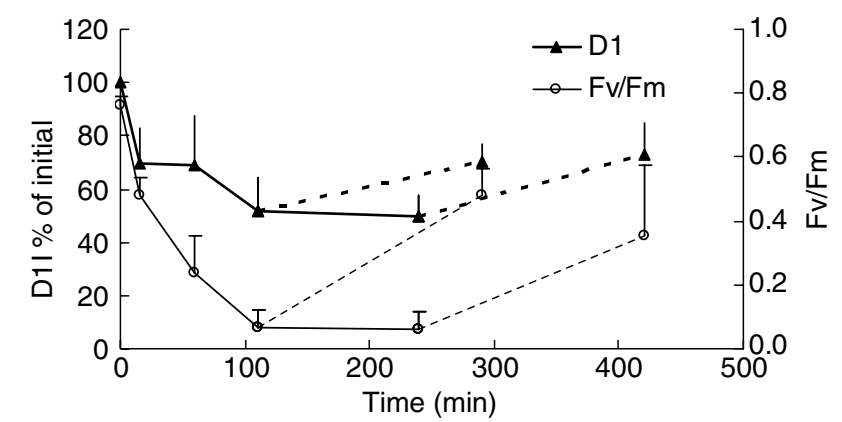

Fig. 3. The effect of $1500 \mu \mathrm{mol}$ photons $\mathrm{m}^{-2} \mathrm{~s}^{-1}$ (solid line) and corresponding recovery in dim light after high irradiance (dashed line) on the amount of D1 protein (triangles) and $F_{\mathrm{v}} / F_{\mathrm{m}}$ (circles) in Ulva lactuca $(n=4-6$, bars represent SD). 


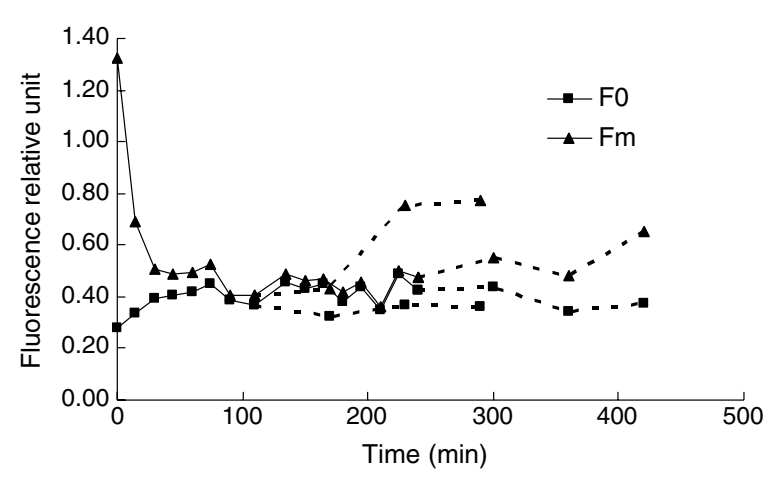

Fig. 4. The effect of $1500 \mu \mathrm{mol}$ photons $\mathrm{m}^{-2} \mathrm{~s}^{-1}$ (solid line) and corresponding recovery in dim light after high irradiance (dashed line) on $F_{0}$ (squares) and $F_{\mathrm{m}}$ (triangles) in Ulva fasciata $(n=4)$.
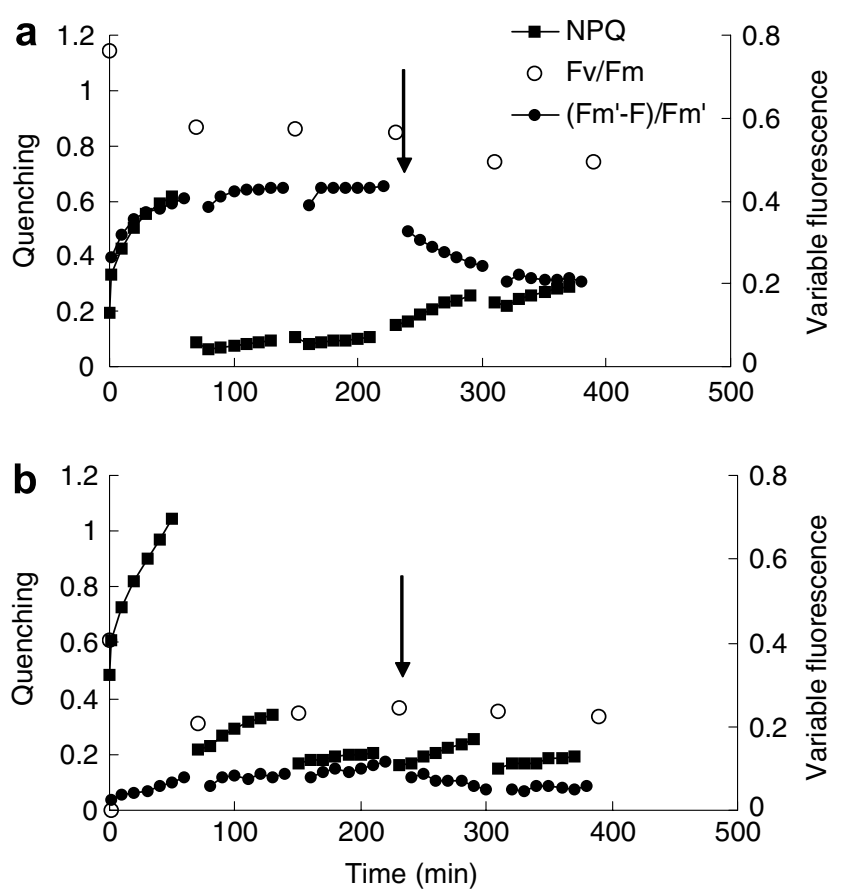

Fig. 5. The effect of $800 \mu \mathrm{mol}$ photons $\mathrm{m}^{-2} \mathrm{~s}^{-1}$ on NPQ (squares), $\left(F_{\mathrm{m}}^{\prime}-F_{\mathrm{t}}\right) / F_{\mathrm{m}}^{\prime}$ (filled circles) and $F_{\mathrm{v}} / F_{\mathrm{m}}$ (circles) in PES nutrient sufficient (a) and PES nutrient deficient (b) Ulva fasciata. Arrows indicate change to low total inorganic carbon concentration. An hour of light exposure is followed by a dark period of approximately $6 \mathrm{~min},(n=5$, except last $F_{\mathrm{v}} / F_{\mathrm{m}}$ point $(\mathrm{B}) n=3$ ).

NPQ during the following two hours of low carbon (Fig. 5).

\subsection{Ratio oxygen evolution/ETR}

The ratio between oxygen evolution and estimated ETR measured at one saturating non- inhibitory irradiance level remains stable even after long exposure to high excess irradiances in $U$. fasciata (with the average ratios ranging between 0.21 and 0.28 , average $\mathrm{SD} \pm 0.03$ of all samples, over the different high irradiance exposure periods and following recovery periods), which is in agreement with previous point ETR measurements in Ulva spp. measured at one irradiance level [35].

\subsection{Spectrophotometric data}

There were no significant differences of overall absorptance $(400-700 \mathrm{~nm})$ in thallus of $U$. fasciata at exposure to high irradiances or after the recovery period. Neither was there any decrease of any specific wavelength at high light exposure. This makes it unlikely that there was a breakdown of chlorophyll or other light catching pigments during high light exposure. However, during recovery following a high light exposure there was a trend of decreasing absorption around $680 \mathrm{~nm}$ and between 410 and $500 \mathrm{~nm}$, indicative of chlorophyll breakdown in dim light. For example, when compared to control within a series $(0 \mathrm{~min}$ high irradiance exposure), an average difference of $-0.05 \pm 0.07 \mathrm{AU}$ was detected at $680 \mathrm{~nm}$ in thalli being subjected to three hours recovery in dim light (following a 110 min high light exposure). This trend was consistent when the same samples were compared to the adsorption of samples that had been exposed to high irradiancy for 110 and $240 \mathrm{~min}$ $(-0.15 \pm 0.11$ and $-0.11 \pm 0.13$ respectively $)$.

\section{Discussion}

\subsection{High light responses}

The rapid decrease of D1 and oxygen evolution showed damage to PSII and photoinhibition of electron transport. The fact that the degradation of D1 levelled off, as well as photoinhibition, after half an hour to one hour, showed that an acclimation took place and that photoinhibition was no longer accelerating. The overall ability of non-photochemical quenching of chlorophyll fluorescence, NPQ, was not responsible for the acclimation since NPQ decreased together with the photosynthetic performance at $1500 \mu \mathrm{mol}$ photons $\mathrm{m}^{-2} \mathrm{~s}^{-1}$. Absorption remained high at $1500 \mu \mathrm{mol}$ photons $\mathrm{m}^{-2} \mathrm{~s}^{-1}$, which showed that light was still captured and there were no pigment breakdown to reduce incoming energy. However, since photoinhibition no longer was accelerating after reaching a certain level, the amount of light reaching the still active PSII units would likely have decreased. An explanation for such a decrease of energy to the still active centres can be that damaged PSII centres protected functional neighbours. There have been reports in literature that damaged reaction centres still connected to the antenna can act as permanent excitation quenchers [36] and damaged or inactivated PSII can protect functional neighbours from further damage $[25,37,38]$

At high irradiances, the breakdown of the D1 protein has been proposed to be an "emergency sacrifice" as a means of reducing incoming light energy when other photoprotective strategies fail to protect PSI from irreversible damage c.f. [22]. In the marine angiosperm, Zostera, reductions of the amount of newly synthesized D1 protein has been reported as a consequence of prolonged high irradiance [39]. In previous experiments where shade grown Ulva were transferred to high irradiance, there was a 
decrease of $F_{\mathrm{v}} / F_{\mathrm{m}}$ the first day with partial recovery after a few days in high irradiance [18], which indicates, when compared to the data in this study, that breakdown of D1 can be important as an initial response to a sudden irradiance change in Ulva.

However, at the lower irradiance $800 \mu \mathrm{mol}$ photons $\mathrm{m}^{-2} \mathrm{~s}^{-1}$ NPQ was effective both in nutrient sufficient and deficient Ulva at the onset of light, while the additional stress caused by low DIC availability decreased the NPQ in the nutrient deficient Ulva as compared to nutrient sufficient in this study.

\subsection{Non-photochemical quenching and photoinhibition}

The decrease of the NPQ ability showed a correlation to D1 breakdown and photoinhibition. The recovery to a higher NPQ ability followed closely the recovery of D1 protein and the ability of photosynthetic electron transport measured as oxygen evolution or ETR. Even though no pigments appeared to have been broken down in high irradiance exposure, chlorophyll breakdown took place at recovery, which showed that pigments adjustment to a lower level can occur at the same time as the ability of NPQ is regained. These results point to the necessity of functional PSII assemblages for NPQ to occur. A likely explanation for such a dependence on photosynthesis is the fact that NPQ requires acidification of lumen that occurs through photosynthetic electron transport $[9,10,19]$. Further $q_{\mathrm{N}}$ remained high, a measurement of non-photochemical quenching in relation to the variable fluorescence [40], which supports a positive correlation between functional PSII centres and the ability of non-photochemical quenching of chlorophyll fluorescence. The variable fluorescence in light corresponded to oxygen evolution rates, which is in agreement with literature that inactive centres are unable of performing variable chlorophyll fluorescence [41].

When doing measurements in field using PAM-chlorophyll fluorescence at photoinhibitory conditions, one should be aware of that the full capacity for NPQ of algae may not always be displayed when measured after a period of strong photoinhibitory light, while at more modest irradiances NPQ can be effective in protecting algae from damage. Net D1 degradation can be expected to occur when there is a combination of a drop of NPQ and low $F_{\mathrm{v}} / F_{\mathrm{m}}$. However, the levels of D1 decreased less at strong light in $U$. fasciata and $U$. lactuca compared to the corresponding $F_{\mathrm{v}} / F_{\mathrm{m}}$, which indicates that care has to be taken in directly relating a low $F_{\mathrm{v}} / F_{\mathrm{m}}$ to a corresponding drop in D1 levels. In higher plant leaves with an effective NPQ, a drop of $F_{\mathrm{v}} / F_{\mathrm{m}}$ was not correlated to D1 breakdown, while D1 breakdown occurred in leaves with a low ability of NPQ and at low $F_{\mathrm{v}} / F_{\mathrm{m}}$ values [42].

\subsection{Ecological implications}

As mentioned in the introduction high photosynthetic rates can increase $\mathrm{pH}$ in close proximity to algae. However,
Ulva has an ability to adapt to a change in $\mathrm{pH}$ and the alga has two principal modes of DIC uptake; one mode is operating at lower or normal $\mathrm{pH}$ of seawater and the carbon utilization is dependant on external dehydration of $\mathrm{HCO}_{3}^{-}$to $\mathrm{CO}_{2}$ catalyzed by Carbonic Anhydrase; The second mode is operating at high $\mathrm{pH}$ and the DIC uptake is mainly dependent on a direct, inducible, uptake of $\mathrm{HCO}_{3}^{-}$ that is dehydrated to $\mathrm{CO}_{2}$ inside the cell [43]. During $\mathrm{pH}$ fluctuations there can be a lag in the full onset of $\mathrm{HCO}_{3}^{-}$ uptake in Ulva [43]. When switching between these modes Non-Photochemical Quenching can be important in alleviating excess energy. DIC limitation increases or accentuates photoinhibition, as a larger portion of the captured energy becomes in excess when less energy is consumed for carbon assimilation. This is demonstrated by the increased NPQ at lower DIC concentrations of the PES nutrient sufficient Ulva presented in this study. Algae in dense stands can also be subjected to depletion of nutrients, such as nitrogen [4]. At such conditions low $\mathrm{CO}_{2}$ availability can add to the stress effect and cause photoinhibition to a level were NPQ is malfunctioning, as indicated by the lowered ability of NPQ in PES nutrient deficient Ulva at low carbon in this study. Under such circumstances, where the captured irradiance is in excess, the sacrifice of D1 can be a mean of avoiding further damage with irreversible effects, i.e. bleaching of Ulva in the field $[3,4]$. Thus, the ability to decrease the amount of active PSII units at exposure to high irradiance is likely to play a major role for survival in hours with excess irradiance when NPQ can malfunction. Ulva will be able to regain growth at more modest irradiances caused by overcasts, high tide, a later hour or by reducing the amount of chlorophyll.

\section{Abbreviations}

DIC dissolved inorganic carbon

ETR electron transport rate

$F_{0} \quad$ minimal chlorophyll fluorescence in dark adapted sample (not reduced)

$F_{\mathrm{m}} \quad$ maximal chlorophyll fluorescence in dark adapted sample (reduced)

LHC light harvesting complex

NPQ non photochemical quenching

OEC oxygen evolving complex

PAM pulse amplitude modulated

PAR photosynthetic active radiation $(400-700 \mathrm{~nm})$

PSII photosystem two

$q_{\mathrm{N}} \quad$ non photochemical quenching in relation to variable fluorescence

\section{Acknowledgements}

This study received support from Magnus Bergvalls foundation. Alon Singer, Sara Jonasson, Martin Ekman and Johan Klint are gratefully acknowledged for assistance in protein determinations. Sven Beer and Sophia Ekengren 
are kindly thanked for valuable comments and suggestions on the manuscript, Petter Carr for language suggestions and Lennart Axelsson for providing Ulva lactuca.

\section{References}

[1] F. Gevaert, A. Creach, D. Davoult, A. Migne, G. Levavasseur, P. Arzel, A.C. Holl, Y. Lemoine, Laminaria saccharina photosynthesis measured in situ: photoinhibition and xanthophyll cycle during a tidal cycle, Mar. Ecol. Prog. Ser. 247 (2003) 43-50.

[2] I. Gomez, F.L. Figueroa, P. Huovinen, N. Ulloa, V. Morales, Photosynthesis of the red alga Gracilaria chilensis under natural solar radiation in an estuary in southern Chile, Aquaculture 244 (2005) 369-382.

[3] K. Bischof, G. Peralta, G. Krabs, W.H. van de Poll, J.L. PerezLlorens, A.M. Breeman, Effects of solar UV-B radiation on canopy structure of Ulva communities from southern Spain, J. Exp. Bot. 53 (2002) 2411-2421.

[4] E. Malta, J.W. Rijstenbil, P.E.M. Brouwer, J.C. Kromkamp, Vertical heterogeneity in physiological characteristics of Ulva spp. mats, Mar. Biol. 143 (2003) 1029-1038.

[5] K.S. Choo, J. Nilsson, M. Pedersen, P. Snoeijs, Photosynthesis, carbon uptake and antioxidant defence in two coexisting filamentous green algae under different stress conditions, Mar. Ecol. Prog. Ser. 292 (2005) 127-138.

[6] L. Axelsson, C. Larsson, H. Ryberg, Affinity, capacity and oxygen sensitivity of two different mechanisms for bicarbonate utilization in Ulva lactuca L. (Chlorophyta), Plant, Cell Environ. 22 (1999) 969978.

[7] S. Beer, The acquisition of inorganic carbon in marine macrophytes, Isr. J. Plant Sci. 46 (1998) 83-87.

[8] P.G. Falkowski, J.R. Raven, Carbon acquisition and assimilation, in: P.G. Falkowski, J.R. Raven (Eds.), Aquatic Photosynthesis, Blackwell Science, Inc., Malden, MA, USA, 1997, p. 130.

[9] P. Horton, M. Wentworth, A. Ruban, Control of the light harvesting function of chloroplast membranes: The LHCII-aggregation model for non-photochemical quenching, FEBS Lett. 579 (2005) 42014206.

[10] A. Kanazawa, D.M. Kramer, In vivo modulation of nonphotochemical exciton quenching (NPQ) by regulation of the chloroplast ATP synthase, PNAS Biophys. 99 (2002) 12789-12794

[11] P. Muller-Moule, P.L. Conklin, K.K. Niyogi, Ascorbate deficiency can limit violaxanthin de-epoxidase activity in vivo, Plant Physiol. 128 (2002) 970-977.

[12] W.W. Adams, B. Demmig-Adams, K. Winter, Relative contributions of zeaxanthin-related and zeaxanthin-unrelated types of "highenergy-state" quenching of chlorophyll fluorescence in spinach leaves exposed to various environmental conditions, Plant Physiol. 92 (1990) 302-309.

[13] A.V. Ruban, A. Young, P. Horton, Modulation of chlorophyll fluorescence quenching in isolated light harvesting complex of Photosystem II, Biochim. Biophys. Acta 1186 (1994) 123-127.

[14] F.L. Figueroa, C. Nygård, N. Ekelund, I. Gómez, Photobiological characteristics and photosynthetic UV responses in two Ulva species (Chlorophyta) from southern Spain, J. Photochem. Photobiol. B Biol. 72 (2003) 35-44.

[15] S. Markager, Light absorption and quantum yield for growth in five species of marine macroalgae, J. Phycol. 29 (1993) 54-63.

[16] C.B. Osmond, J. Ramus, G. Levavasseur, L.A. Franklin, W.J. Henley, Fluorescence quenching during photosynthesis and photoinhibition of Ulva rotundata Blid, Planta 190 (1993) 97-106.

[17] L.A. Franklin, G. Levavasseur, C.B. Osmond, W.J. Henley, J. Ramus, Two components of onset and recovery during photoinhibition of Ulva rotundata, Planta 186 (1992) 399-408

[18] W.J. Henley, G. Levavasseur, L.A. Franklin, C.B. Osmond, J. Ramus, Photoacclimation and photoinhibition in Ulva rotundata as influenced by nitrogen availability, Planta 184 (1991) 235-243.
[19] T. Shikanai, Y. Munekage, K. Kimura, Regulation of proton-toelectron stoichiometry in photosynthetic electron transport: physiological function in photoprotection, J. Plant Res. 115 (2002) 3-10.

[20] Y. Yamamoto, Quality control of photosystem II, Plant Cell Physiol. 42 (2001) 121-128.

[21] K.K. Niyogi, Photoprotection revisited: genetic and molecular approaches, Annu. Rev. Plant Physiol. Plant Mol. Biol. 50 (1999) 333-359.

[22] K. Asada, The water-water cycle in chloroplasts: scavenging of active oxygens and dissipation of excess photons, Annu. Rev. Plant Physiol. Plant Mol. Biol. 50 (1999) 601-639.

[23] T. Henmi, M. Miyao, Y. Yamamoto, Release and reactive-oxygenmediated damage of the oxygen-evolving complex subunits of PSII during photoinhibition, Plant Cell Physiol. 45 (2004) 243-250.

[24] T. Hundal, I. Virgin, S. Styring, B. Andersson, Changes in the organization of photosystem II following light-induced D1-protein degradation, Biochim. Biophys. Acta 1017 (1990) 235-241.

[25] E.M. Aro, I. Virgin, B. Andersson, Photoinhibition of Photosystem II. Inactivation, protein damage and turnover, Biochim. Biophys. Acta 1143 (1993) 113-134.

[26] T.J. Avenson, A. Kanazawa, J.A. Cruz, K. Takizawa, W.E. Ettinger, D.M. Kramer, Integrating the proton circuit into photosynthesis: progress and challenges, Plant Cell Environ. 28 (2005) 97-109.

[27] E. Darko, G. Varadi, Y. Lemoine, E. Lehoczki, Defensive strategies against high light stress in wild and D1 protein mutant biotypes of Erigeron canadensis, Aust. J. Plant Physiol. 27 (2000) 325-333.

[28] G. Varadi, H. Polyanka, E. Darko, E. Lehoczki, Atrazine resistance entails a limited xanthophyll cycle activity, a lower PSII efficiency and an altered pattern of excess excitation dissipation, Physiol. Plant 118 (2003) 47-56

[29] D.P. Häder, M. Lebert, R.P. Sinha, E.S. Barbieri, E.W. Helbling, Role of protective and repair mechanisms in the inhibition of photosynthesis in marine macroalgae, Photochem. Photobiol. Sci. 1 (2002) 809-814

[30] L. Provasoli, Media and prospects for cultivation of marine algae, in: A. Wattanabe, A. Hattori (Eds.), Cultures and collections of algae, Proceedings US-Japan Conf. Hakone, Jpn. Soc. Plant Physiol., 1968, pp. 63-75.

[31] D. Strbac, M.A. Rodrigues, C.P. dos Santos, D.O. Hall, Chloroplast isolation from Laminaria digitata (Phaeophyceae): a reproducible methodology yielding photosynthetically active chloroplasts, Planta 195 (1994) 138-141.

[32] W.J. Hurkman, C.K. Tanaka, Solubilization of plant membrane proteins for analysis by two dimensional gel electrophoresis, Plant Physiol. 81 (1986) 802-806.

[33] T. Rabilloud, Solubilization of proteins for electrophoretic analyses, Electrophoresis 17 (1996) 813-829.

[34] C. Larsson, L. Axelsson, Bicarbonate uptake and utilization in marine macroalgae, Eur. J. Phycol. 34 (1999) 79-86.

[35] H. Carr, M. Björk, A methodological comparison of photosynthetic oxygen evolution and estimated electron transport rate in tropical Ulva (Chlorophyceae) species under different light and inorganic carbon conditions, J. Phycol. 39 (2003) 1125-1131.

[36] R.E. Cleland, A. Melis, P. Neale, Mechanism of photoinhibition: photochemical reaction center inactivation in system II of chloroplasts, Photosynth. Res. 9 (1986) 79-88.

[37] H.Y. Lee, Y.N. Hong, W.S. Chow, Photoinactivation of photosystem II complexes and photoprotection by non-functional neighbours in Capsicum annuum L. leaves, Planta 212 (2001) 332-342.

[38] L.A. Franklin, A.W.D. Larkum, Multiple strategies for a high light existence in a tropical marine macroalgae, Photosynth. Res. 53 (1997) $149-159$.

[39] Y.S. Flanigan, C. Critchley, Light response of D1 turnover and photosystem II efficiency in the seagrass Zostera capricorni, Planta 198 (1996) 319-323.

[40] K. Rohácek, Chlorophyll fluorescence parameters: the definitions, photosynthetic meaning, and mutual relationships, Photosynthetica 40 (2002) 13-29. 
[41] I. Vass, S. Styring, T. Hundal, A. Koivuniemi, E.-M. Aro, B. Andersson, Reversible and irreversible intermediates during photoinhibition of photosystem II: Stable reduced QA species promote chlorophyll triplet formation, Proc. Natl. Acad. Sci. USA. Biophys. 89 (1992) 1408-1412.
[42] A. Thiele, K. Winter, G.H. Krause, Low inactivation of D1 protein of photosystem II in young canopy leaves of Anacardium excelsum under high-light stress, J. Plant Physiol. 151 (1997) 286-292.

[43] L. Axelsson, H. Ryberg, S. Beer, Two modes of bicarbonate acquisition in Ulva lactuca, Plant, Cell Environ. 18 (1995) 439-445. 